\title{
Coronary thrombus in 34-year-old female patient with 4G/4G polymorphism in the PAI-1 gene
}

\author{
Sinan Varol a,*, Muhsin Kalyoncuoglu ${ }^{\text {b }}$, Burak Ayça ${ }^{\text {a }}$, İrfan Şahin a , Gökmen Kum a , \\ Sevgi Özcan a, Ertugrul Okuyan ${ }^{a}$ \\ a Bagcilar Training \&' Research Hospital, Cardiology, Istanbul, Turkey \\ b Haseki Training \& Research Hospital, Cardiology, Istanbul, Turkey
}

\section{A R T I C L E I N F O}

Article history:

Received 30 August 2015

Received in revised form 7 March 2016

Accepted 9 March 2016

Available online 7 April 2016

\section{Keywords:}

Coronary

Thrombus

PAI-1 gene

Polymorphism

\begin{abstract}
A B S T R A C T
Genetic factors and hypofibrinolytic state may contribute to the likelihood of developing in myocardial infarction (MI) in young women rather than traditional risk factors. High plasminogen-activator inhibitor-1 (PAI-1) level and PAI-1 gene polymorphism have been shown to be associated with thrombotic events such as myocardial infarction, deep venous thrombosis, and stroke. We determined 4G/4G polymorphism in a 34-year-old female patient with subacute anterior myocardial infarction and coronary thrombus in left anterior descending artery on coronary angiogram.

C 2016 The Society of Cardiovascular Academy. Production and hosting by Elsevier B.V. All rights reserved. This is an open access article under the CC BY-NC-ND license (http://creativecommons.org/licenses/by-nc-nd/4.0/).
\end{abstract}

\section{Introduction}

The pathogenesis of myocardial infarction (MI) is complex and multifactorial, including multiple interacting environmental and genetic factors. Traditional risk factors such as hypertension, diabetes mellitus, and hypercholesterolemia are less pronounced in the younger patients in development of the myocardial infarction. Therefore, additional factors such as genetic factors and hypofibrinolytic state may contribute to the likelihood of developing in the myocardial infarction and may be required to determine in young participants. ${ }^{1}$ Plasminogen-activator inhibitor-1 (PAI-1) is a member of serpin superfamily of protease inhibitors and a key regulatory protein of fibrinolysis cascade by inhibiting plasminogen activators which are tissue plasminogen activator (t-PA) and urokinase (u-PA). ${ }^{2}$ High plasma PAI-1 levels have been shown to be associated with atherosclerosis, restenosis, and in the pathogenesis of disorders associated with thrombotic events such as myocardial infarction and deep venous thrombosis. ${ }^{2-4}$ It was reported that PAI-1 gene polymorphism such as $4 G / 5 G$ and $4 G / 4 G$ genotypes has been associated with the higher gene expression and higher PAI-1 levels in the circulation resulting in an increased risk for thrombotic events such as MI and stroke. ${ }^{5-10}$

\footnotetext{
* Corresponding author. Tel.: + 00905556223410 .

E-mail addresses: sinanvarol@gmail.com (S. Varol), mkalyoncuoglu80@gmail.com (M. Kalyoncuoglu), burakayca@yahoo.com.tr (B. Ayça),dr.irfansahin@gmail.com (İ. Şahin), dr_gkum@hotmail.com (G. Kum), sevgibozcan@gmail.com (S. Özcan), dreokuyan@hotmail.com (E. Okuyan).

Peer review under responsibility of The Society of Cardiovascular Academy.
}

\section{Case report}

A 34-year-old female patient had been admitted for chest pain of about 5 days, which accelerates with exertion and resolves with rest. She has no any history of smoking, alcohol, drug abuse, systemic disease, or family history of cardiovascular disease. Blood pressure was $115 / 70 \mathrm{~mm} \mathrm{Hg}$ and heart rate was 88 BPM. Cardiac auscultation was normal heart sounds with no murmur. Other physical examination findings were normal. ECG revealed loss of R progression on V2-3, ST segment elevation on V2-5, and new developed deep inverted $\mathrm{T}$ waves on V1-V6 (Fig. 1). Two weeks before symptoms, ECG was normal with positive $T$ waves. Echocardiography was normal with absence of any wall motion abnormalities. Blood tests were troponin $0.419 \mathrm{mcg} / \mathrm{L}, \mathrm{CK}-\mathrm{MB}<21 \mathrm{ng} / \mathrm{mL}$. Coronary angiogram revealed long intracoronary thin thrombus adjusted to endothelium at LAD artery (Fig. 2). Because of lack of response to repeated dosages of intracoronary nitroglycerin, and typical thin trombus appearance, vasospastic angina was excluded. Patient has received tirofiban infusion for 24 hours. Repeat coronary angiogram has shown partial resolution of coronary thrombus (Fig. 3). During hospital care, chest pain diminished with enoxaparine $6000 \mathrm{IU}$ twice daily, clopidogrel $75 \mathrm{mg}$, acetyl salicylic acid $300 \mathrm{mg}$, metoprolol $50 \mathrm{mg}$, and nitrate therapy. Statin therapy was not initiated because of absent conventional risk factors. ECG follow-up showed that resolution of ST segment elevation, but negative $\mathrm{T}$ waves were persisted. Warfarin was started and acetyl salicylic acid dose was adjusted as $100 \mathrm{mg}$ per day. Patient has been discharged with prescribing same medical treatment. Genetic analysis showed that negative for protrombin gene mutation (G20210A), Factor V Leiden 


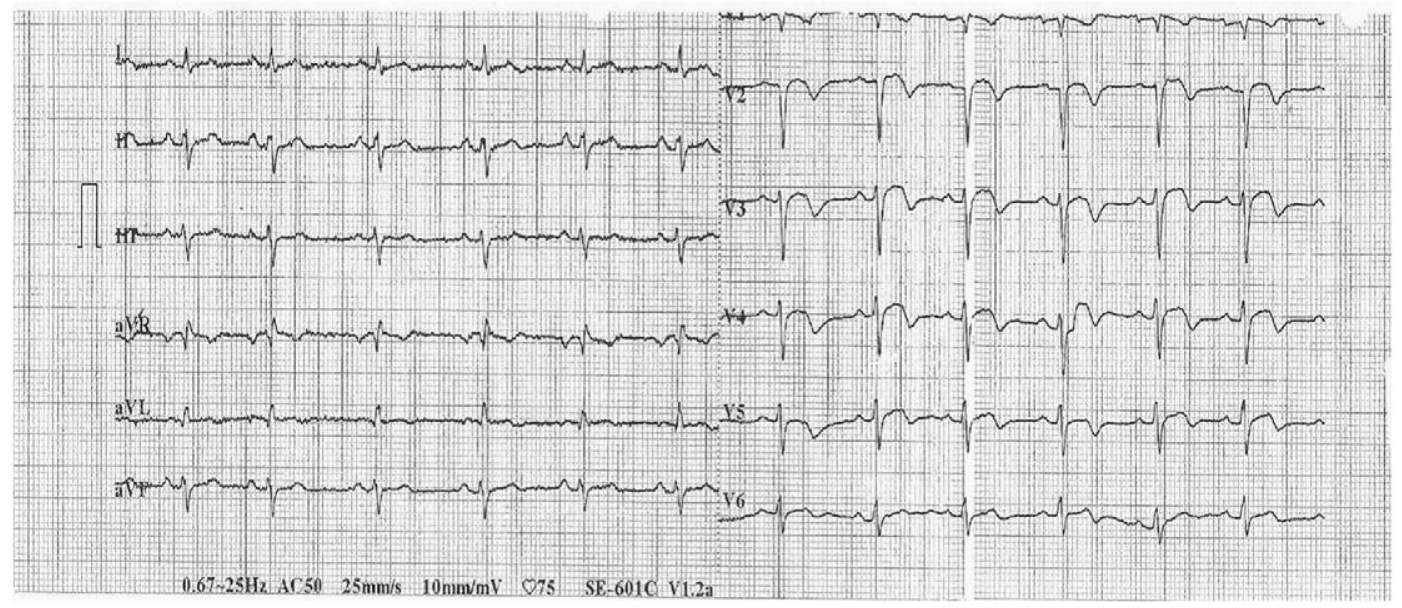

Fig. 1. ECG on admission

(G1691A), Factor XIII V34L, MTHFR (C677T), Protein C and Protein S mutation, antithrombin III, antiphospholipid antibody.

Lupus anticoagulant had a weak positive result of 1.35 , thought as clinically irrelevant (cut-off value: negative: $<1.2$; weak positive: $1.2-$ 1.5 , positive: $>1.5$, markedly positive: $>2.0$ ). Heterozygot MTHFR (A1298C) mutation has been revealed as positive, but homosistein levels were normal, and there was weak evidence of developing thrombus with this mutation in current literature. Protrombine Activator Inhibitor 1 (PAI-1) serpine 4G/4G mutation has been revealed by genetic analysis. This mutation has been known to be a high risk for thrombotic events. So we thought it was responsible for this event. During followup, the patient has complained of intermittent chest pain with short duration as couple of minutes and resolves spontaneously. After 2 months, ECG findings were similar with negative T waves on V1-V6, and there was short duration of angina attacks. At 4 months, ECG revealed that negative T wave was only at V2-V3 leads, and at 5 months, ECG was normal with positive T waves and clinically asymptomatic.

\section{Discussion}

An increased capacity to form blood clots or decreased fibrinolytic capacity due to high plasma PAI-1 levels has been shown to play an important role in the pathogenesis of disorders associated with thrombotic events such as MI and ischaemic stroke. ${ }^{1,8,11,12}$ It was also found that

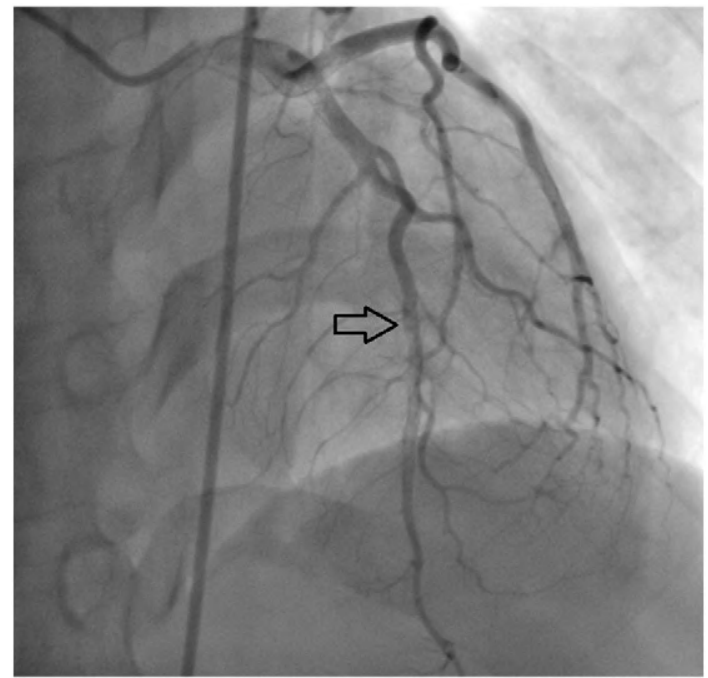

Fig. 2. Coronary thrombus on left anterior descending artery. increased levels of PAI-1 were associated with coronary endothelial dysfunction, plaque progression, and vulnerability leading to unstable angina pectoris and acute myocardial infarction. ${ }^{2,13-15}$ It has been also reported that several genetic variations in coagulation and fibrinolytic proteins were associated with the development of the risk of MI. ${ }^{7}$ The PAI-1 gene known as SERPIN 1 gene in humans is located on chromosome $7 q 22 .{ }^{4}$ Two genetic variations, which were guanosine insertion/ deletion, $-6754 G / 5 G$, and -844 G/A promoter polymorphisms in the PAI-1 gene, have been associated with increased PAI-1 levels and linked to various vascular diseases such as MI and deep vein thrombosis. ${ }^{5,7,13,16,17}$ Homozygosity for the deletion genotype (4G/4G) has been associated with higher gene expression than those associated with the insertion genotype $(5 \mathrm{G} / 5 \mathrm{G}$ ) resulting in higher PAI-1 levels in the circulation and an increased risk for venous thrombosis, pulmonary thromboembolism, and MI through impairment of fibrinolytic function by elevated PAI-1 activity. ${ }^{5,7,8,16,18}$ Plasma levels of PAI-1 have a wide and peak in the morning, whereas concentrations of t-PA exhibit less prominent circadian variation, and a relative hypofibrinolytic state may occur in the morning with increased platelet reactivity. That condition may contribute to the increased risk of MI seen during this period. In a study, it has been also reported that morning increase in PAI-1

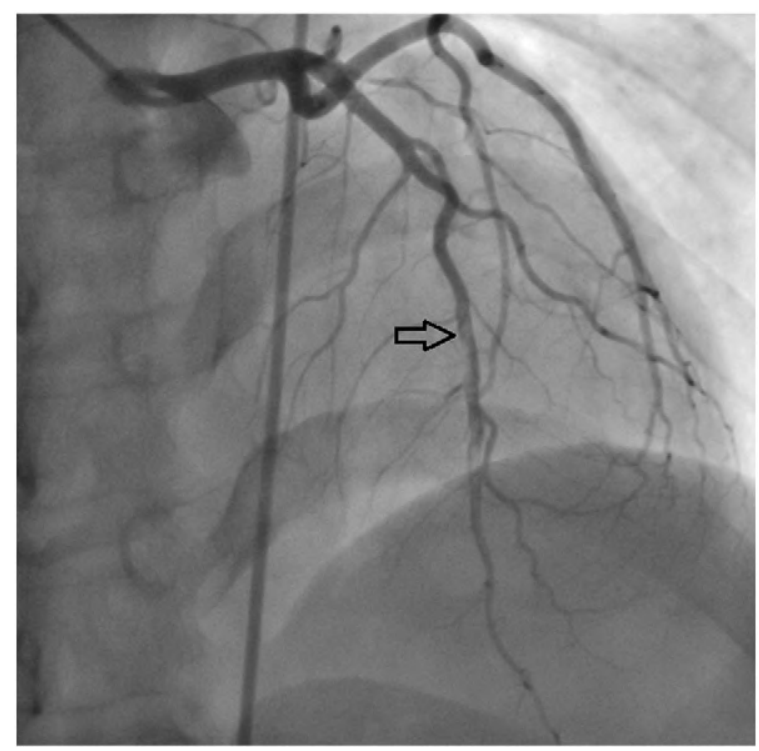

Fig. 3. After tirofiban infusion, thrombus with partial resolution persisted on the left anterior descending artery. 
activity may be determined in $4 G / 4 G$ genotype subjects. ${ }^{13}$ Boekholdt et al. showed that homozygosity for the PAI-1 4 G allele was significantly associated with increased risk of myocardial infarction. ${ }^{7}$ In a large Japanese study, the $P A I 4 G / 5 G$ polymorphisms appeared to be a risk factor for myocardial infarction in women. ${ }^{19}$ In a recent study, Ismail et al. found that PAI-1 genotype was higher in Egyptian patients with myocardial infarction. There was about twofold increased risk of MI associated with $4 G 4 G+4 G 5 G$ compared with $5 G 5 G$. However, in that study, the PAI-1 polymorphism $(4 G)$ was not found associated with MI, whereas modest risk could not be excluded. ${ }^{13}$ While the mentioned data suggested positive association between the development of MI and PAI-1 gene polymorphism, Atherosclerosis, Thrombosis, and Vascular Biology Italian Study Group (2003), did not find any association between PAI-1 gene polymorphisms and the development of acute MI at a young age (under the age of 45 years).$^{20}$ Ding et al. also found that PAI-1 gene polymorphisms were associated with high plasma PAI-1 levels, whereas they were not associated with MI or stroke. ${ }^{21}$

There are some studies in the literature that reported that PAI-1 antigen levels are positively correlated with cholesterol, LDL-cholesterol, VLDL, and triglyceride levels and negatively with HDL cholesterol. ${ }^{4,18,22}$ In addition, it was suggested that the $4 \mathrm{G} / 4 \mathrm{G}$ genotype has been reported to be associated with high cholesterol levels. ${ }^{22}$ It was also claimed that the increase in PAI-1 levels resulting from the activation of the reninangiotensin system and hypertension in subjects with the $4 G / 4 G$ genotype. ${ }^{4}$ It was also found that smoking by patients carrying the $4 \mathrm{G}$ allele may have an important impact on the frequency of MI. ${ }^{13}$ Consequently, data about the relation of PAI-1 with myocardial infarction are still inconclusive and contradictory.

The etiology of cardiovascular disease is multifactorial and strongly involves genetic and environmental factors. The interaction of genetic and traditional risk factors such as smoking, hypertension, hypercholesterolaemia may have a role in the development of MI. So that, identifying them for primary prevention early in life, especially in the presence of genetic predisposition, is important. Despite aforementioned data, the clinical use of fibrinolytic markers to determine coronary risk offers only marginal value and no data available suggest analysis of fibrinolytic function in addition to traditional risk scores. We propose that the determination of well-described polymorphisms in the PAI-1 promoter and other components of the fibrinolytic system as a novel risk factor in addition to traditional risk factors is important.

\section{Conclusion}

Certain genetic disorders have tendency to myocardial infarction. Genetic testing should be considered for patients with young age, atypical presentation, and who have specific angiographic findings.

\section{Conflict of interest}

No conflict of interest.

\section{References}

1. Siegerink B, Meltzer ME, de Groot PG, Algra A, Lisman T, Rosendaal FR. Clot lysis time and the risk of myocardial infarction and ischaemic stroke in youn women: results from the RATIO case-control study. Br J Haematol 2011;156:252-258.
2. Figueras J, Monasterio J, Domingo E, Meneses B, Nieto E, Cortadellas J, Garcia-Dorado D. Prothrombotic profile in patients with vasospastic or non vasospastic angina and nonsignificant coronary stenosis. Thromb J 2011;9:10.

3. De Young MB, Tom C, Dichek DA. Plasminogen activator inhibitor type 1 increases neointima formation in balloon-injured rat carotid arteries. Circulation 2001;104: 1972-1976.

4. Katrancioğlu, Nurkay, et al. PAI-1 4G/4G gene polymorphism is associated with higher serum lipid level in Turkish population. Cumhuriyet Med J [S.l.] 2011 Sep.;33(3): 307-311http://dx.doi.org/10.7197/cmj.v33i3.1008000938 (ISSN 1305-0028 . Available at: <http://dergi.cumhuriyet.edu.tr/cumucmj/article/view/1008000938>. Date accessed: 30 Dec. 2015).

5. Assawamakin A, Sriratanaviriyakul N, Lalerd Y, et al. Meta-analysis of the plasminogen activator inhibitor-1 (PAI-1) gene with insertion/deletion $4 \mathrm{G} / 5 \mathrm{G}$ polymorphism and its susceptibility to ischemic stroke in Thai population. Asian Biomed 04/2012;6(2):203-217 (Available at: < https://www.researchgate.net/publication/ 224221857_Meta-analysis_of_the_plasminogen_activator_inhibitor-1_PAI-1_gene_ with_insertiondeletion_4G5G_polymorphism_and_its_susceptibility_to_ischemic stroke_in_Thai_population>. Date accessed: 30 Dec. 2015. doi:).

6. Bang CO, Park HK, Ahn MY, Shin HK, Hwang KY, Hong SY. 4G/5G polymorphism of the plasminogen activator inhibitor-1 gene and insertion/deletion polymorphism of the tissue type plasminogen activator gene in atherothrombotic stroke. Cerebrovasc Dis 2001:11:294-299.

7. Boekholdt SM(SMB), Bijsterveld NR, Moons AHM, et al. Genetic variation in coagulation and fibrinolytic proteins and their relation with acute myocardial infarction. Circulation 2001;104:3063-3068.

8. Balta G, Altay C, Gurgey A. PAI-1 gene 4G/5G genotype: a risk factor for thrombosis in vessels of internal organs. Am J Hematol 2002;71:89-93.

9. Eriksson P, Kallin B, van't Hooft FM, Bavenholm P, Hamsten A. Allele-specific increase in basal transcription of the plasminogenactivator inhibitor 1 gene is associated with myocardial infarction. Proc Natl Acad Sci U S A 1995;14:1851-1855.

10. Spronk HMH, van der Voort D, ten Cate H. Blood coagulation and the risk of atherothrombosis: a complex relationship. Thromb J 2004;2:12.

11. Kohler HP, Grant PJ. Mechanisms of disease; plasminogen-activator inhibitor type 1 and coronary artery disease. New Engl J Med 2000;342:1792-1801.

12. Guimaraes Ana HC, Bruijne Emile LE, Lisman T, et al. Hypofibrinolysis is a risk factor for arterial thrombosis at young age. Br J Haematol 2009;145:115-120.

13. Ismail S, Abdel azeem AA, Abdel Hamid MA, Nowier SR, Morad $H$. The role of $4 \mathrm{G} / 5 \mathrm{G}$ genetic polymorphism of plasminogen activator inhibitor-1 gene in myocardial infarction among Egyptans. Life Sci J 2011;8(1):32-39 (Avaible at: https:// www.google.com.tr/url? sa $=$ t\&rct $=j \& q=\& e s r c=s \&$ source $=$ web\&cd $=1 \&$ ved $=$ 0ahUKEwjum_e3gITKAhVI_SwKHWvrCv8QFggaMAA\&url=http\%3A\%2F\%2Fwww. lifesciencesite.com\%2Flsj\%2Flife0801\%2F06_4152life0801_32_39.pdf\&usg= AFOjCNFUJ3U-xrc7LSfz9zT0XIdw BDyNw\&bvm=bv.110151844,d.bGg\&cad=rja).

14. De Young MB, Tom C, Dichek DA. Plasminogen activator inhibitor type 1 increases neointima formation in balloon-injured rat carotid arteries. Circulation 2001;104: 1972-1976.

15. Figueras J, Monasterio Y, Lidon RM, et al. Thrombin formation and fibrinolytic activity in patients with acute myocardial infarction or unstable angina. In-hospital course and relationship with recurrent angina at rest. J Am Coll Cardiol 2000;36:2036-2043.

16. Oszajca K, Wronski K, Janiszewska G, Bienkiewicz M, Bartkowiak J, Szemraj J. The study of t-PA, u-PA, and PAI-1 genes polymorphisms in patients with abdomimal aortic aneurysm. Mol Biol Rep 2014;41:2859-2864.

17. Buchholz T, Lohse P, Rogenhofer N, et al. Polymorphisms in the ACE and PAI-1 genes are associated with recurrent spontaneous miscarriages. Hum Reprod 2003;18(11): 2473-2477.

18. Yamada Y, Izawa H, Ichihara S, et al. Prediction of the risk of myocardial infarction from polymorphisms in candidate genes. N Engl J Med. 2002;347:1916-1923.

19. Atherosclerosis, Thrombosis, and Vascular Biology Italian Study Group (2003). No evidence of association between prothrombotic gene polymorphisms and the development of acute myocardial infarction at a young age. Circulation 2003;107: 1117-1122.

20. Ding J, Nicklas BJ, Fallin MD, et al. Plasminogen activator inhibitor type 1 gene polymorphisms and haplotypes are associated with plasma plasminogen activator inhibitor type 1 levels but not with myocardial infarction or stroke. Am Heart J 2006;152(6):1109-1115.

21. Tsantes AE, Nikolopoulos GK, Bagos PG, Bonovas S, Kopterides P, Vaiopoulos G. The effect of the plasminogen activator inhibitor-1 4G/5G gene polymorphism on the thrombotic risk. Thromb Res 2008;122:736-742.

22. Boncoraglio GB, Bodini A, Brambilla C, Carriero MR, Ciusani E, Parati EA. An effect of the PAI-1 4G/5G polymorphism on cholesterol levels may explain conflicting associations with myocardial infarction and stroke. Cerebrovasc Dis 2006;22(2-3):191-195. 